wound, I think is proved by the evidences of obstructed venous circulation, which the above condition of the limb reveals.

Remarks. We were not aware, at the time of the publication of the above case, that there was any other on record in which the limb had been saved after a wound of both the artery and vein; but it appears that John Hunter made an endeavour, at any rate, to effect this object. In a manuscript copy of his lectures, from notes taken by Dr. John Clarke, with the inspection of which we have recently been favoured by the kindness of their present possessor, the following entry occurs:- "A. B. was working with a knife, and ran it into his thigh, and so wounded the crural artery where it passes through the third head of the triceps. A tumour was formed, with pulsation. A peculiar thrill arose in it. A tourniquet was applied, and a director passed into the wound. The parts were laid freely open; the artery found. A ligature was then made above and below the orifice. The vein bled, and was taken up too."

Unfortunately, the event of this case is not given; but it is more probable that the attempt to save the limb was successful than otherwise, from the very fact of the case being so dismissed, without any mention of gangrene or other evil consequence. At any rate, it is interesting to know that this great master of surgery thought it reasonable to attempt the preservation of the limb under these circumstances.

\section{Britional Communtatations.}

\section{PATHOLOGICAL AND THERAPEUTICAL CON- SIDERATIONS RELATIVE TO INFLAM- MATION AND FEVER.}

By C. Handfield Jones, M.B., F.R.S., Physician to St. Mary's Hospital.

[Continued fiom page 910.]

5. Tarious forms of Inflammation. The most important distinction to be made between different instances of inflammation relates to the degree in which they approximate to the sthenic or to the asthenic type. On a due appreciation of this, the success of treatment wholly depends. In sthenic inflammation, the tissue of the part is prominently concerned, its nutritive force is deranged and perverted, rather than simply depressed; it is inapt for functional work, but highly resentful of stimulation. 'l'he latter, if powerful, may subdue the morbid state of the tissue, but if it fail to do this, exasperates it. Tonics that would induce contraction of the blood-vessels through their nerves, and so diminish the hyperæmia, irritate the diseased tissue, and increase the morbid action. The healthy play of the tissue in attraction and repulsion of blood is exchanged for morbid attraction, and so accumulation of blood takes place. The effective remedies are such as annul this state of tissueirritation, depressants, contrastimulants, or tissue sedatives as I have termed them. Thus antimony is an efficient lungsedative in sthenic bronchitis or pneumonia, and colchicum an articular sedative in sthenic gout and synovitis. An excellent example of this form of inflammation is so-called acute eczema, which is aggravated by arsenic, and cured by leeches, lead lotion, salines, and antimony.

In asthenic inflammation, on the other hand, the tissue is much more quiescent, much less susceptible of irritation, and tolerant of stimuli. It takes no notably active part in the inflammatory process, but (if a surface) simply allows the transudation of cell-developing exudation. The phenomena are chiofly dependent on vaso-motor nerve paralysis, and consequently diminish and cease under the use of nervine tonics. Thus quinine is most beneficial in asthenic pneumonia. Arsenic in asthenic rheumatism and eczema. It is most striking in the latter disorder to find the hyperæmia, exudation, and heat of skin, cease under the tonic remedy; one is involuntarily reminded of the result of galvanising the divided sympathetic nerve. The sthenic character is commonly ex. hibited in the earlier period of inflammation, and is replaced by the asthenic in the later. Either, however, may exist during the whole course of the disease. Sthenic inflammation is usually excited by some locally acting irritant, but it may be produced as well as asthenic by vaso-motor nerve paralysis, or may even originate spontaneously as in whitlow. The resemblance of the visible phenomena of sthenic and asthenic inflammation may be so close, that nothing but careful testing with remedies can make the distinction possible. Like chemical reagents, our drugs appeal to forces we cannot otherwise observe. It is, however, always to be remembered, that the perfectly typical cases of disease are rare, and that the majority are mixed, or intermediate between various types, and partake most of one or other. The term substhenic would designate correctly many such instances.

6 . The modifications imposed on inflammation by the locality in which it occurs, the tissue which it affects, are noteworthy. In serous tissues, it is prone to spread over the surface, and to pour out copious effusions, which may be serous, fibrinous, or purulent; these mostly are more or less mixed. Even rheumatic inflammation commonly causes suppuration in this tissue. In mucous tissue, inflammation is also spreading, and gives rise early to exudation, which, as long as the basement surface is entire, contains no large amount of albumen, but chiefly the characteristic slimy principle mingled with varying amounts of pus.corpuscles and immature epithelial particles. The high vascularity of many mucous membranes, and the thinness and delicacy of their epithelium, very much promote the early occurrence of exudation of the fluid part of the blood, and even sometimes the escape of the solid corpuscles. In cutaneous tissue the spreading tendency is much less, and is chiefly manifested in asthenic forms of inflammation, as for instance, erysipelas. Exudation does not occur to any notable amount as long as the epidermis remains attached. In the subcutaneous and areolar tissue, sthenic inflammation soon becomes circumscribed by fibrinous effusion, in the more central parts of which suppuration takes place. In asthenic inflammation, the morbid process is not thus circumscribed, and spreads often extensively, causing great mischief and peril. Solid masses of tissue, as liver, kidneys, brain, muscles, are far less prone to be the seat of suppuration than surfaces, or areolar tissue. One cause of this is, that in these dense textures exudation takes place much more sparingly. Another is, that large masses of tissue persevere more steadily in their normal nutrition than thin membranes, and are far less liable to deviate into inflammation.

Acute and chronic designate the rate at which inflammation proceeds. Acute may be asthenic, chronic may be sthenic.

7. Reaction (morbid) signifies that the vital forces of the part or system affected are not utterly or almost overborne and prostrated, but that they resent, and are stimulated after a manner by the morbid impression. It is most true there is no such thing as an intelligent striving of the natural forces against the cause of disease, to throw it off, as it were; the fact being simply that they are excited to unusual and abnormal manifestations. They are excited to increased action; but that action is not in the right direction, it is injurious and wasteful. Still it shows that the power of the tissues is not extinguished, that they are yet life.full. He who has stood by the bed-side of the patient in malignant dysentery or cholera, and painfully witnessed the utter non-response of the system to all remedies, or he who has been striving for a long period to upstay a weakly nervous system, that is evermore relapsing into debility and prostration, is quite rejoiced at the signs of good, outspoken, hearty reaction. 'There is hope to be able to calm and guide the one, there is almost a seinse of despair in the attempt to raise and sustain the other. The signs of (excessive) reaction are essentially those of inflammatory or sthenic fever, viz., vigorous action of the heart, strong full pulse, hot skin, red lips, increased tolerance of blood-letting. Local reaction is equivalent to sthenic inflammation and its results. Collapse, on the contrary, is marked by debility, feeble-pulse, cold skin, blueish lips, diminished tolerance of blood-letting. Its local manifestation is gangrene.

Increased action is a term often used, and often I think not correctly understood. It is essentially the same as reaction above described. It is therefore clear that it does not mean real increase of healthy power, more vigorous functional action, but only a greater amount of action of some lind. Compared to healthy action, it is like a river bursting its banks and spreading destruction all round, as contrasted with the same stream duly restrained, irrigating meadows, and turning water-mills.

The above remarks have reference of course to morbid states. There is healthy reaction, as after a shower-bath; and healthy increased action, as when a gland or a muscle perform its functions vigorously.

8. Causes of Inflammation. If friction be kept up for some length of time on a part which has been unaccustomed to it say the hand, as in rowing, inflammatory phenomena are produced. Blisters form on the surface, i.e., the epidermis is 
raised by an exuclation of fibrino-serous fluid from the cutis beneath, which is unduly injected with blood. If the irritating cause be withdrawn, the hyperæmia gradually ceases, and the effusion is reabsorbed. Here we have a clear case of inflam. mation produced by a locally acting mechanical cause. Fffects essentially similar can be produced by irritants of a different kind, as heat, mustard, cantharides, the poison of gonorrhœa, the galvanic current. It is a point worthy of remark, that the susceptibility to inflammatory irritation from the above mentioned agencies differs much in different persons. One person can bear a mustard poultice for half an hour or more, another not for five minutes; one person's slin is readily blistered by cantharides, another's with great difficulty; the novice's hand is soon made "raw" by the oar, the practised oarsman's not at all. All this implies a difference in the nutritive power of the skin in different individuals; in some it is easily deranged from its normal operation, in others it adheres to it pertinaciously. The sanie is true of all other tissues, if any one is easily deranged from its normal mode of life and nutrition, that part is the weak point, the one which disease is sure to assail. This local weakness may be congenital, or acquired in various ways. When the whole system is possessed of considerable resisting power to the various perturbing causes, the fortunate possessor is said justly to have a strong constitution. This is a very different thing from having great muscular force.

Traumatic inflammations, though usually on a much larger scale, are essentially similar to those above considered. The injury deranges the normal nutritive actions of the part, prostrating them at first in a greater or less degree, and subsequently diverting them into morbid attraction and retention of blood, or into this combined with more or less of vaso-motor nerveparalysis; in other words, into sthenic or substhenic intlammation.

Another class of inflammations are such as are produced by the reception of a substance into the blood, which acts as an irritant on one or more parts. Thus arsenic absorbed from a wound, or mucous surface, inflames the stomach; cantharides, swallowed, infiames the minary organs; and so on. The poison may be generated in the system, as that of gout, or inhaled as those of variola and erysipelas.

In a third class of inflammations, we may affirm that the exciting cause is some imponderable. When malaria causes dysentery; or influenza bronchitis, or diarrhoea; or when some unknown influence excites cynanche tonsiliaris, we have instances of the kind in question. To say, without further consideration, that these are produced by the reception of some atmospheric poison into the blood, and that they belong to the preceding class, scems to me an assertion very weally supported. It will be well worth while to attempt some closer inquiry into the possible or probable causation of these inflammations. It cannot be doubted that cold, or cold and damp, may produce such effects, yet it is equally certain that they are not the only or chief causes. Catarrhal and other in flammations constantly arise without any exposure to cold and wet. The arencies which give rise to malarious disease and influenza are quite unknown to us, and it seems at any rate prudent for the present to regard them as of a distinct kind from other demonstrable and ponderable poisons. They may t.e rather peculiar forces, or states of matter, than isolable substances. It may be of some advantage if we take the injurious action of damp cold as an illustrative instance of their action. Here we do not think of a poison circulating in the blood, but of an impression made on some part of the surface, which is resented by some internal part. This injurious impression may be scarcely felt at the time it takes place, and its effects scarcely perceived till some hours after. See a remarkable instance of the effects of unfelt irritation in Brown-Séquard's Lecture XI (Lancet, 1858, p.5\%2). This is more striking than analogous cases where the irritating cause (a worm) affected the mucous surface. Sometimes it is immediate in its action, as when the sufferer feels the cold strike to his chest. In the Jatter case the result stands in no relation with any cutaneous sensation that we are cognisant of, and it has often a peculiar enfeebling or paralysing effect. Before proceeding further, I would say that the opinion that cold causes inflammation by repelling the blood from the surface, seems to ine a very insufficient account of its action. If this were true, the severe cold of the arctic regions would far more often excite internal inflammation than is found to be the case.

I will now adduce some actual instances of the effects produced by cold, and endeavour to interpret them so as to show their bearincr upon the production of internal inflammations. A writer in Household Words gives the following description of the cold of the Black Sea, evidently from personal experience. "It is bitterly cold (thin penetrating rain falling every now and then.) That clammy deadly cold of these climates, against which no clothes seem able to protect you. It is a cold which is not felt in the chest, nor hands, nor feet, as our cold in Europe is ; but it is sure to strike first at the stomach. You were well just now, and trying with all the philosophy at your command to be jovial under difficulties; suddenly you are seized with agonizing pains just below the chest. In vain sou try to make light of it. You are obliged to lean for support against the first thing or person at hand. Your extremities have become chilled and useless; you sit and double yourself up, hoping something from warmth and quiet; at last you lie down, and writhe in the intensity of your pain. If you are driven to take brandy (hot brandy and water is best), you feel a peculiar sickness for some minutes, and then the pain slowly subsides; but it leaves you stupid and depressed for hours afterwards, trembling and nervous. The only way to give yourself a chance of escape is by winding some twenty yards of silken or woollen sash tightly round your loins and ab domen. It is the custom of the country, the dress of the peasant and prince, and you will soon understand it has not been adopted without a reason. 'This was the commencement of that sickness which carried off numbers of our troops. The doctors called it cholera; it was only cold." Without fully agreeing with the last sentence, I yet entertain no doubt that the effects so graphically described were really produced by damp and cold, and there can be no question that such an influence would powerfully promote the operation of cholerapoison. The protection afforded by the ample sash can only be explained, I think, on the view of its warding off the operation of cold, and this opinion is confirmed by $\mathrm{Mr}$. $\mathrm{R}$. Martin's authority. He writes " the ample turban and khummerbund meet our eye at every step; the former to defend the head from the direct rays of a powerful sun; the latter for the purpose of preserving the important viscera of the abitomen firom the deleterious impressions of cold. The klummmerbund is certainly a most valuable part of the dress, and one that is extensively imitated throughout India by Europeans, in the form of a cotton or flannel waistband worn generally next the skin." Similar effects of cold are not unfrequent in our own country. A very robust medical man stated to me that during exposure to severe cold in Scotland, he had several times experienced a sensation about his epicastrium, as if he had " a toothache in his stomach." It does appear to me, that in these common facts, evidenced by the habitual practice of large masses of mankind, and approved by the sober judgment of the educated physician, there lies a truth which science has yet scarcely appreciated. The operation of cold described in the first quoted passage is evidently chiefly upon the solar plexus. 'l'his great nervous centre is as it were smitten with an influence half paralysing, half irritating, which appears to bo the effect of cold acting on the contiguous cutaneous surface. 'This is surely a very remarkable circumstance, and but partially explicable by our present knowledge of the laws of nervous actions. How comes it to pass that the action of cold on the cutaneous extremities of some intercostal nerves shonld fall so peculiarly on a remote sympathetic centre, and this too situated so peculiarly en face of the part primarily affected? Why should not some other centre be affected? The phenomenon, however, is not an isolated one. The arrest of epistaxis by the application of cold to the back, of the catamenia by cold and wet to the feet, and of pulmonary hremorrhage by ice to the spine and cardiac region, prove that an impression may be trarismitted from cutaneous nerves to the vaso-motor of a remote internal part. 'The interesting fact lately ascertained by Brown-Séquard and Tholozan, is of the same kind. They find that immersion of one hand or foot in very cold water lowers notably the temperature of the corresponding part, and of this only. I have observed a rery marked state of goose-skin of the anterior part of the trunl produced by the sudden application of cold water to the back: the skin at the upper semi-circumference of the nipples was rendered quite pale.

In all these instances, we have evidence of the action of cold through incident nerves upon various nervous centres, manifested in certain efferent nerves. It is, therefore, not inconceivable that, in certain cases, the effect may be more specially manifested in the centre itself. This seems certainly to be the case in the sudden deaths that have been occasioned by drinking cold water when the frame was exhausted. The scdative action of the cold upon the gastric nerves is communicated to the solar and cardiac plexus, and through the latter paralyses 
the motion of the heart. To proceed. A man travelling on the outside of a coach is exposed to a cold wind blowing in his face, and in consequence becomes amaurotic to a notable extent. He is cured, not by depletion or mercury, but by stimulation of the skin of the face, forehead, temples. (Graves, Clin. Med., 1st edit., p. 398.) The not unfrequent occurrence of paralysis of the portio dura from exposure to cold is, I am aware, often attributed to rheumatic inflammation causing effusion around the nerve in the Fallopian canal; but, besides that there seems little or no evidence to prove this from post mortem examination, it is very unlikely to hold good as the true explanation of all cases, seeing that in those common affections, viz., facial rheumatism and tympanic inflammation, paralysis of the portio dura is rarely observed. Romberg quotes J. Frank to the effect that seven of his patients were suddenly attacked with this paralytic affection from getting up in the moming and putting their heads out of window, and drawing back because they found it very cold. The supervention of the paralysis in these cases was surely too quick to be ascribed to inflammation and exudation. Dr. Graves records a case, p. 415 , in which paraplegia came on in a man aged 32 , as the result of exposure to cold and wet. Both motion and sensation were lost, or nearly so. The hands, about three weels afterwards, were similarly affected, but to a less extent. He remarks: "T'o what can we attribute these symptoms, except to the influence of cold acting on the nervous filaments of the cutaneous surface of the limbs, extending its morbid impression to the spine, and thence reacting on the nerves so as to produce impairment of the power of motion and diminished sensation? The man certainly had no symptom of cerebral or spinal disease, nor was there anything connected with the state of the nervous centres which would lead to the supposition that the paraplegia was the result of an irritation originally affecting the brain or spinal cord." I have recently observed a case under Dr. Sibson's care, in St. Mary's Hospital, in which there had come on gradually considerable impairment of rnotion and sensation in the lower and upper limbs, with failure of masticating power. The symptoms dated from exposure to wet, he having stood on wet grass a whole morning, and the affection having commenced the next day. After about four months, he died in a kind of faint. The autopsy was very carefully made, but no morbid change was found in the brain except some slight congestion, and a little serum in the lateral ventricles. The part of the spinal cord corresponding to the lower dorsal and upper lumbar regions appeared to be firmer than usual, whilst the upper part was much softer than this; but sections of both these portions revealed nothing unnatural in appearance, or worthy of remarl. Careful microscopic examination of the spinal cord and pons Varolii detected nothing abnormal; there were no glomeruli, and no granular exudation on the vessels.

The following case is given by Dr. Copland, art. "Paralysis", p. 20. A gentleman, who had resided many years in an interuropical country, on his royage across the Atlantic in the winter season, "was seized with general palsy of the powers of voluntary motion immediately after prolonged exposure to cold and wet. 'The functions of the brain were unaffected; and neither pain nor uneasiness was felt in the neck, or in any part of the spinal column, under any circumstances of position, Hexure, rotation, or pressure. No evidence of inflammatory action, or of congestion in the spine, could be detected. Cutaneous transpiration was suppressed, and the bowels were costive and torpid; but he retained the sensibility of the surface, and command over the sphincters. He was treated at first upon the supposition of either serous effusion or vascular congestion having taken place in the spinal canal, but without receiving any benefit. He ultimately, however, quite recovered, by having a frequent recourse to warm baths containing stimuläting substances."

To my own mind, the above mentioned cases render the conclusion legitimate, that cold operating on the cutaneous surface may so atfect one or more nervous centres throngh incident nerves, that they are more or less entirely disabled from discharging their furction. The centre belonging to a motor nerve, a sensory, or a special nerve, may be affected in this way. What is the exact nature of the change effected, we do not know; but it certainly seems not to involve any irremediable lesion of the structural elements. For all practical purposes, we had better think and speak of the change as a dynamic one-a simple loss of power-which we find to be restored by influences of an opposite lind to those which depresserl it. In the case first cited, of the action of cold upon the solar plexus, the effect is partly pain, partly paralysis-just such a combination as is common in various neuralgiæ, where the affected part is numb and painful, to which Romberg applies the term anæsthesia dolorosa. The condition of the centre and of the nerves has much to do in determiniug the result of the impression of cold. If both are healthy, the centre will reflect the impression as a stimulus to vaso-motor nerves. If the centre is feeble, the nerves too sensitive, or the impression excessive, the dynamic organ may be gravely disordered, paralysed, or irritated; and this state may spread and extend to other associated or combined centres. It is very probable that this state of paralysis, or paralysis and irritation, is really an inhibitory phenomenon, the cold acting in the same way as the galvanism in the experiment quoted lower down. The same explanation will, I think, apply to the cases recorded by Stanley and Spencer Wells, of the occurrence of paralysis in connexion with inflamed kidneys; and to those mentioned by Graves, of the same consequence, after gastro. enteritis. The morbid impressions conveyed by ganglionic nerves to the cord, set up in the grey matter a state incompatible with its functional action. It is a very important fact, that if this state continue unremoved for some length of time, it is very apt to become permanent, or at least to yield very slowly to remedies. I am, of course, aware of the view main tained by Dr. Gull, that, in these cases, there exists inflamma tion and softening of the cord, which is not discoverable with. out microscopic examination; but I greatly doubt the possibility of admitting this view as expressing what invariably happens. Moreover, it is quite possible that a kind of degeneration might after a time take place in the part of the cord which at first was only functionally paralysed. Dr. Gull has recently published an interesting case of acute paraplegia, proving fatal in about three weeks from cystitis and peritonitis, in which the most careful microscopy detected nothing abnormal in the cord. (Guy's Hospital Reports, 1858.) Among the cases cited by Dr. Graves, in his lecture on Paraplegia, is a very interesting one which had been under Dr. Hutton's care. In this man's case, an almost sudden amendment took place in his paraplegis (which came on soon after prolonged exposure to cold and wet) on the dilatation of an urethral stricture by a bougie. Warm baths, and friction to his limbs, completed the cure. The rapid improvement in this case seems to me better ex plained on the view that the paralysis was of inhibitory origin, than on any other. The close stricture was a source of irritation to the spinal cord; and, on diminishing this, the grey matter of the centre resumed its healthy play. The same view will apply, I think, to the two cases related by Sir B. Brodie, pp. $12-13$ of his work On Local Nervous Affections. A gentleman, lamed by pain in one instep, was cured in a quarter of an hour by passing a bougie for a stricture. A lady was cured of a similar pain by successful treatment of internal hæmorrhoids. These cases were instances of the irradiation of sensations, or at least of centripetal impressions; they are more familiar than those in which paralysis is the result, but the mechanism of both is the sane. Some peculiar condition of the nervous centre determines the production of paralysis instead of pain. Perhaps, however, the neuralgic state in a sensory, and the paralytic in a motor nerve, may be closely allied, the result differing according to the different endowment. If neuralgia in the anremic is "the prayer of the nerve for healthy blood", this surely implies a functional debility, which in a motor nerve would be paralysis or enfeeblement. The same idea is also linted to us by the occurrence of anresthesia dolorosa.

Now, to apply the above views to the production of internal inflammations, if it be admitted that the impression of cold conveyed to a nervous centre may there occasion such change as eventuates in the paralysis of musculo-motor nerves, it seems reasonable to conclude that the same impression acting on a sympathetic centre may cause paralysis of vaso-motor nerves. 'This, as already described, sets up active byperæmia and increased local heat and tissue-change, which, in states of predisposition, readily passes into actual inflammation. It does not form an oljection to the above theory of interval inflammations being produced by external impressions, to say that the effect is of much longer duration than the exciting cause. Instances can easily be adduced in which irritation of brief duration, causing no actual local lesion, has produced atiding disorder at a distance. Duchenne relates how, in Faradising 8 case of local paralysis of sensation with a powerful current, he once incautiously applied the current to the healthy muscles. The effect was, that sharp pains came on in the excited part, spread to the neck and head, and continued.many days. After. wards, the patient had cerebral symptoms, requiring the use of 
derivatives. Such accidents frequently happened to him before experience had taught him to be wary of exciting sensitive parts too strongly.

Whether or not the above explanation be correct, as to the mode in which inflammation is set up in a remote part, as the consequence of a morbid impression upon the external or in ternal surface, there is no question that inflammations do originate in this way. Brown-Sequard relates that, "in animals in which the spinal cord has been divided at the level of the third or fourth lumbar vertebra, so that the posterior limbs camnot give any pain, and that, also, no irritation can be propagatel from them to the viscera of the head, the chest, and most of those of the abilomen," no marked alterations were seen "similar to those which are so often observed in man and animals accidentally burnt, except in the bladder and rectum, and neighbouring organs. On the contrary, when the section of the spinal cord was made as high as the third dorsal vertebra, I have seen all the abdominal viscera in a state of congestion, very much resembling inflammation in many parts, with serous infiltrations and ecchymoses, two days after one of the legs had been burnt by boiling water.... In two cases, on animals on which the trunks of the sciatic and crural nerves in one limb had been divided as high as possible, I have not found a state of marked congestion in any viscus three days after I harl carbonised this limb from the toes up to the middle of the thigh."

Mr. Paget cites the case of a testicle becoming inflamed to the degree of having lymph and pus deposited in its structure, as the consequence of the irritation of a fragment of calculus impacted in a healthy urethra. He sees no other explaration that can be given, except that the exercise of the nervous force in the testicle was disturbed through the medium of the morbidly affected nerves in the urethra. Dr. Graves relates a case in which a chicken-bone lodged in the œesophagus for about an hour, and produced much irritation and inflammation. About the third day ensuing, the patient got a violent rigor, "which terminated in a profuse perspiration, and ushered in a well markerl inflammation of the neck of the bladder." Dr. Graves believes this to have been an instance of disease being propagated in a reflex manner to other and more distant parts. The so-called sympathetic ophthalmia, and the experience of Mr. I'aget as to slight conjunctivitis of the left eye being excitel by microscoping long with the other, are again instances of the same linit. So is the cure of ophthalmia as the result of the extraction of a carious tooth, recorded by Dr. Campbell.

In all cases of this kind, it is manifest that the nutrition of the secondarily inflamed part must be in a weakened state be forehand, so that its equilibrium is disturbed more readily than that of other parts: it is, in fact, predisposed. This is one element in the process; another is the relation of its nerves to those incident from the seat of irritation.

9. The views above offered are, I think, applicable to many cases of orlinary inflammatory disease, but by no means to all. In particuiar, I conceive the influenzal affections belong to the class which acknowledges a poisonous agent diffused through the circulation. 'The rheumatic, on the other hand, I am very ruuch inclined to refer, at least in part, to the cold-excited class. How far the local irritant action of cold-as, $e . g$., on the bronchial tubes-may operate as a cause of inflammation, seems to me doubtful. If it were a potent or frequent one, the intense colll of the Arctic regions would surely produce more marked efficts than the milder cold of temperate climes. The previous state (the predisposing) is probably in all cases of prime importance in determining the result of impressions of cold, not acting as local irritants. Thus, in persons subjected to tropical heats, a chill produces effects which would not occur in those who had undergone no such debilitating influences. Persons in our own country, who are much exposed to heat, as bakers, are peculiarly liable to "take cold". The nervous centres are rendered more impressionable and mobile by the high temperature, and so more sensitive to cold.

10. In the above, mention has chiefly been made of the nerves and the tissues as factors in the process of inflamma. tion; but there is reason to regard the blood as greatly, if not equally, concerned, In the case of such disease as the exanthemata, it is the vehicle of the original, as well as the source of the multiplied virus, which acts as an irritant to produce the various inflammations. But, further, the observations of $M$. Vanzetti (Brit. and For. AIed. Review, July 1859), as to the results of interrupting the flow of blood through the main artery of an inflamed limb, go to show that, when the tissues are simply intlamed, the presence of moving blood acts upon them as an irritant, maintaining and increasing that morbid condition; and that the withdrawal of this cause of irritation for a time allows the morbid state to subside, after which the bloodflow may again be restored without reproducing the inflammation. These observations go far to justify venesection, employed as a means of diminishing the stress and force of the circulation.

[To be continued.]

\section{CONTRIBUTIONS TO CLINICAL SURGERY.}

By Oliver Pemberton, Esq., Surgeon to the General Hospital, and Lecturer on Surgical Pathology at Sydenham College, Birmingham.

\section{VI.-Excision of the KNeE.}

THE operation of excision of the knee in preference to amputation of the thigh, has now been resorted to in so many instances, in this the second epoch of its trial, that we might fairly conclude that its history, its complications, and its shortcomings had been told; that the cases in which it should be selected were recognised; that it was an operation in which the public possessed confidence as well as the profession; and that private individuals had experienced its benefits as well as hospital patients ; in a word, that it was established in reputation as strongly as excision of the elbow, or as amputation at the ankle-joint. But, it is not so. We have yet to learn very much in connection with this operation before we can associate it with these and other well tried procedures of surgery.

The mere absence of excessive fatality will not be sufficient to establish its position. No surgeon, at all acquainted with the amount of shock, of hæmorrhage, and the other attendant circumstances of excision of the knee, will contend for one moment that the same amount of danger to life in general follows its performance, as does amputation of the thigh.

The great question is the utility of the limb preserved. The mechanic and the rustic have hitherto been the subjects to illustrate its desirability. We want to know how far they can make use of their limbs in their respective callings.

The time has gone by for us to look with deep interest on a rescued limb merely as such, in consequence of excision of the knee. We must now learn how far the remnant that has escaped will enable its possessor to labour for his living with the same facility as he would have done with a wooden substitute. A sufficient time has now elapsed for the rendering a true account on this important point, and both the public and the profession must anxiously expect to be told of the wearing powers possessed by limbs that underwent the operation in the the earlier portions of the last nine years.

Where the subjects submitted to operation had not attained full development of limb, the possession of this knowledge becomes of paramount importance, inasmuch as on the evidences afforded by such cases, more especially in regard to the question of subsequent parity of growth, will depend the establishment or the total rejection of the proceeding in similar instances for the future. With this view strongly before me, I shall submit to the profession what I may term " the further history of an excised knee-joint in the ungrown subject," com prising a period of nearly six years, and I shall add to this my experience of certain complications which may arise in connection with the operation generally, by a reference to the particulars of typical cases.

CASE I. E. F., aged 12, a pale, strumous looking boy, of much intelligence, was admitted under my care in the General Hospital, Birmingham, December 20th, 1853, suffering from disease of the left knee, of fourteen months' duration. 'The following was the state of the joint. The leg of the affected limb formed a right angle with the thigh, from which position it could only be slightly altered by the exercise of great force, occasioning acute pain. The circumference of the joint was larger by three inches and a half than that of the opposite one. The integuments were shiny and painful. The apertures of four sinuses were apparent; and three of these communicated with carious bone. These openings were situated as follows: one over the external condyle; one over the internal condyle; one over the anterior surface of the femur; and a superficial one over the head of the fibula. His sufferings were very 